\title{
The pattern of comorbidities in cancer patients in Lagos, South-Western Nigeria
}

\author{
Omolola Salako', Paul T Okediji², Muhammad Y Habeebu' ${ }^{1}$, Omolara A Fatiregun ${ }^{3}$, Opeyemi M Awofeso ${ }^{4}$, Kehinde S Okunade ${ }^{5}$, \\ Ifedayo A Odeniyi ${ }^{6}$, Kahmil O Salawu² and Evaristus $\mathrm{O} \mathrm{Oboh}^{7}$
}

\begin{abstract}
1'Department of Radiotherapy, Lagos University Teaching Hospital, Idi-Araba, Lagos 100254, Nigeria
${ }^{2}$ Research and Development, Sebeccly Cancer Care, Yaba, Lagos 101212, Nigeria

${ }^{3}$ Department of Radiotherapy, Lagos State University Teaching Hospital, Ikeja, Lagos 100254, Nigeria

${ }^{4}$ College of Medicine, University of Lagos, Akoka, Lagos 100254, Nigeria

${ }^{5}$ Department of Obstetrics and Gynaecology, College of Medicine, University of Lagos, Lagos 100254, Nigeria

${ }^{6}$ Department of Medicine, Faculty of Clinical Sciences, College of Medicine, University of Lagos, Lagos 100254, Nigeria

${ }^{7}$ Department of Radiotherapy, University of Benin Teaching Hospital, Benin 300283, Nigeria
\end{abstract}

Correspondence to: Paul T Okediji. Email: chnovpaul@gmail.com

\begin{abstract}
Purpose: Comorbidities have been indicated to influence cancer care and outcome, with strong associations between the presence of comorbidities and patient survival. The objective of this study is to determine the magnitude and pattern of comorbidities in Nigerian cancer populations, and demonstrate the use of comorbidity indices in predicting mortality/survival rates of cancer patients.
\end{abstract}

Methods: Using a retrospective study design, data were extracted from hospital reports of patients presenting for oncology care between January 2015 and December 2016 at two tertiary health facilities in Lagos, Nigeria. Patient comorbidities were ranked and weighted using the Charlson comorbidity index $(\mathrm{CCl})$.

Results: The mean age for the 848 cancer patients identified was $53.9 \pm 13.6$ years, with $657(77.5 \%)$ females and $191(22.5 \%)$ males. Breast $(50.1 \%)$, cervical $(11.1 \%)$ and colorectal $(6.3 \%)$ cancers occurred most frequently. Comorbidities were present in 228 (26.9\%) patients, with the most common being hypertension $(20.4 \%)$, diabetes $(6.7 \%)$ and peptic ulcer disease $(2.1 \%)$. Hypertension-augmented $\mathrm{CCl}$ scores were 0 (15.6\%), 1-3 (62.1\%), 4-6 (21.7\%) and $\geq 7(0.6 \%)$. The mean $\mathrm{CCl}$ scores of patients $\leq 50$ years $(0.8 \pm 0.9)$ and $\geq 51$ years $(3.3 \pm 1.2)$ were significantly different $(p<0.05)$. Patients with lower mean $\mathrm{CCl}$ scores were more likely to receive chemotherapy $(2.2 \pm 1.6$ versus $2.5 \pm 1.9 ; p<0.05)$ and/or surgery $(2.1 \pm 1.5$ versus $2.4 \pm 1.7 ; p<0.05)$.

Conclusion: Comorbidities occur significantly in Nigerian cancer patients and influence the prognosis, treatment outcome and survival rates of these patients. There is a need to routinely evaluate cancer patients for comorbidities with the aim of instituting appropriate multidisciplinary management measures where necessary.

Published: 13/06/2018

Received: 30/11/2017

ecancer 2018, 12:843 https://doi.org/10.3332/ecancer.2018.843

Copyright: (C) the authors; licensee ecancermedicalscience. This is an Open Access article distributed under the terms of the Creative Commons Attribution License (http://creativecommons.org/licenses/by/3.0), which permits unrestricted use, distribution, and reproduction in any medium, provided the original work is properly cited. 


\section{Introduction}

Cancer is one of the most commonly diagnosed conditions globally, and is also a leading cause of death worldwide. The increasing cancer burden in developing countries such as Nigeria is a significant public health problem that governments are grappling with. The GLOBOCAN 2012 report showed that there were 14.1 million new cases of cancer, 8.2 million mortalities from cancer and 32.6 million people living with cancer worldwide in 2012 [1]. Of these huge figures, the major morbidity and mortality burden are borne by developing countries as $70 \%$ of deaths from cancer occur in middle- and low-income nations [2]. With more Nigerian patients presenting to cancer clinics and the increasing availability of cancer care, oncologists are managing more patients with cancer and comorbidities. Bellizzi and Rowland [3] reported that $69-88 \%$ of cancer patients have at least one comorbidity. As a result of this, the treatment of such patients becomes convoluted and its impact on survival and quality of life becomes significant.

Comorbidities are medical conditions that coexist with the disease of interest, but are not related in causality or aetiology to the primary diagnosis [4]. They may occur prior or at the same time as the primary disease. For several years, the influence of these coexisting medical conditions on the outcome of care for the cancer patient has often been ignored. According to Piccirillo and Feinstein [5], a large number of the most frequently used cancer classification systems in clinical practice do not consider critical patient-based prognostic factors such as the general health of the cancer patient-which is dependent on the presence, number and pathophysiological severity of any coexisting illnesses or conditions. These illnesses or conditions that are not as a result of the adverse effect of therapy for cancer, which exist before the cancer diagnosis was made, are referred to as comorbidities [6].

The importance of comorbidities in cancer patients draws from an increasing awareness of their impacts on cancer care and outcome. Recent research by Lund et al [7], Patniak et al [8] and many other authors show that a high level of comorbidity correlates with reduced survival indices of patients with cancer. This can be explained by the increase in mortality caused by the presence of the comorbid conditions. Moreover, the increase in cancer-specific mortality as a result of these comorbid conditions have also been attributed to the use of suboptimal antineoplastic treatment regimens [9, 10], and/or an increase in treatment toxicity leading to reduced treatment compliance [11]. In addition, toxicity arising from cancer therapy can also influence the outcome of care. The presence of at least one comorbid condition has been associated with diagnostic dilemmas and delays in making cancer diagnosis, leading to more advanced disease at the time of final diagnosis [12]. Other effects of multiple comorbidities on cancer patients include an increase in the risk of complications from surgery [13], higher rates of postoperative mortality [14-16], and a greater consumption of medical resources [17].

One of the factors associated with an increasing incidence of cancer worldwide is the increase in life expectancies [18]. Considering that the prevalence of most noncommunicable diseases rises with age, it is easy to understand the increasing prevalence of coexisting medical disorders in cancer patients over their lifespan [19]. Also, advancement in medical therapies has also contributed to the doubling of the prevalence of chronic diseases between 1985 and 2005, and a threefold increase in the proportion of patients with greater than four coexisting medical conditions [20]. In addition, comorbidity has been associated with individuals who have low social support, mental health disorders and high levels of socioeconomic deprivation [21]. This explains in part why patients in developing countries with higher levels of socio-economic deprivation are at greater risk of multiple comorbidities. Furthermore, since comorbidity has been associated with a significant drop in functional reserves and an increased physical frailty, it suggests the reasons why cancer patients in developing countries like Nigeria experience higher levels of treatment-related toxicities and also have suboptimal outcomes [22].

Nigeria has a huge burden of cancer patients, as estimates show that over 102,000 Nigerians are diagnosed with cancer annually, and 5-year prevalence rates of breast, cervical, prostate and colorectal cancer have been put at 37.7\%, 15.4\%, 13.4\% and 3.7\%, respectively $[1,23]$. In addition to this high cancer prevalence, chronic nonmalignant illnesses are also very common as studies have identified significant prevalence rates of illnesses such as diabetes (4.0\%), cardiovascular disease (12\%), bronchial asthma (14-18\%) and others amongst the Nigerian population [24-28]. The World Health Organization estimates the mortality from noncommunicable chronic illnesses to be $818 / 100,000$ of males and $806 / 100,000$ of females in 2012 [29]. There is presently a dearth of information about the prevalence and effects 
of comorbidities on cancer patients in Nigeria. Considering the established effects of comorbidities on cancer care and outcome, it becomes necessary to understand with greater accuracy the magnitude and pattern of comorbidities in Nigerian cancer patients.

Therefore, the general focus of this research is to determine the magnitude and pattern of comorbidities in the Nigerian cancer population, and to elucidate the demographic and social factors that are most responsible for the occurrence of these comorbidities in cancer patients.

\section{Methodology}

\section{Patient selection}

This retrospective study focused on all patients with various types of cancers who presented at the Departments of Oncology and Radiotherapy of the Lagos University Teaching Hospital (LUTH), Idi-Araba, and the Lagos State University Teaching Hospital, Ikeja, for treatment between January 2015 and December 2016. These two public tertiary centres receive the bulk of patients with cancers in Lagos State, surrounding states and the West-African sub-region. Eligible patients were selected on the basis of these criteria: (a) clinical and/or histological diagnosis of a malignancy, (b) ages older than 18 years and (c) diagnosed or treated for a malignancy within the study time frame. Patients with skin cancers and clinical records with missing or unknown data were excluded.

\section{Data collection}

Data were collected from the hospital records of patients who fit into the eligibility criteria. Emphasis was on patient demographics (such as age, hospital number, gender, occupation, religion, marital status and contact information), clinical characteristics (such as type of cancer, histology, grade, stage and presence of comorbidities) and social history. Information about comorbidities was recorded using the Charlson comorbidities index $(\mathrm{CCl})$, which has been validated and tested with huge success [30, 31]. The index was based on weighted measures of 18 different comorbidities (excluding solid tumours) and calculated by adding one point for each decade of life after 40 years-one point for those between 41 and 50 years, two points for 51-60 years, three points for 61-70 years and four points for those $\geq 71$ years. A score of one point for hypertension was added to the index comorbidities, particularly because of the presumed high prevalence of the disease in many cancer patients, and the recent modifications of the $\mathrm{CCl}$ to include hypertension (hypertensionaugmented $\mathrm{CCl}$ ) [32]. Presence of comorbidities was determined by past medical history or present history of any of the index illnesses. Data quality was ensured for accuracy and completeness by the use of well-trained medical personnel and review of collected data by a different independent review team. Histological diagnosis was based on reports written by verified and certified histopathologist from within and outside the study centres.

\section{Data analysis}

All statistical analyses were conducted within the software platform of the IBM Statistical Package for the Social Sciences (SPSS) for Windows, version 20.0. Basic demographic, clinical and social data were presented and analysed using descriptive statistics in the form of frequency tables. Continuous data including $\mathrm{CCl}$ scores were presented in the form of means \pm standard deviation. Associations between mean $\mathrm{CCl}$ and treatment options were determined using independent t-tests. Statistical significance $(p$-values) set at $\leq 0.05$.

\section{Ethical considerations}

Ethical approval for this research was obtained from the Health Research and Ethics Committee of the LUTH, Idi-Araba, and carried out in line with the principles of the Helsinki Declaration. Consideration was made for the confidentiality of data and protection of all data obtained during the course of this research. 


\section{Results}

The analysis included 848 patients who fulfilled the eligibility criteria with various types of cancers seen between January 2015 and December 2016. The mean age was $53.9 \pm 13.6$ years with $191(22.5 \%)$ males and $657(77.5 \%)$ females (Table 1). The majority of the patients were managed for breast cancer $(425,50.1 \%)$.

Breast, cervical, colorectal, prostate and ovarian cancers occurred more often in descending order of frequency, and all together, these five cancers constituted about three-quarters of the patient population (Table 1). Comorbidities were present in 228 (26.9\%) patients and the most commonly used treatment option was chemotherapy $(687,81.0 \%)$. Surgical treatments and radiotherapy were administered to 380 $(44.8 \%)$ and $332(39.1 \%)$, respectively.

The calculation of the total $\mathrm{CCl}$ is presented in Table 2. Each decade after 40 years of age was scored one incremental point till $\geq 71$ years. Hypertension was the most prevalent comorbidity occurring in $173(20.4 \%)$ of patients. This is followed by diabetes mellitus and peptic ulcer disease.

On the basis of $\mathrm{CCl}$ scores, Table 3 shows the proportions of the various scores ranging between 0 and 9 . The bulk of the patients lie between scores 0 and 4 . Patients with $\mathrm{CCl}$ score of 1 have 1.45 times the probability of dying within 1 year, which increases to 4.4 times and above for patients with $\mathrm{CCl}$ scores of 4 and above.

Patients with prostate cancer had the highest mean $\mathrm{CCl}$ scores $(3.7 \pm 1.2)$, followed by lung cancer $(3.4 \pm 1.2)$ and pancreatic cancer $(3.0 \pm 1.2)$. These same set of patients had the highest mean ages in decreasing order-66.5, 66.2 and 61.4 years for prostate, lung and pancreatic cancer, respectively (Table 4). Breast cancer patients had some of the lowest CCl scores with a mean of $2.0 \pm 1.5$ and a mean age of $52.4 \pm 12.7$ years.

Patients with ages 50 years or less had a significantly lower mean $\mathrm{CCl}(0.8 \pm 0.9)$ than those who are at least 51 years or more $(p<0.05$; Table 5). As the ages increased, the chances of developing a comorbid illness increased, with a peak between the ages of 60 and 69 years (Figure 1). There were also significant differences in the mean CCls of patients who either received chemotherapy compared to those that did not $(p=0.05)$, and between those who received surgical treatments and those who did not $(p=0.01)$. However, there was no significant difference in the mean $\mathrm{CCls}$ of patients who did or did not receive radiotherapy for their primary disease $(p=0.52)$.

Table 1. Characteristics of the study population.

\begin{tabular}{|l|c|c|}
\hline & Frequency $(\boldsymbol{n}=\mathbf{8 4 8})$ & $\begin{array}{c}\text { Percentage of total } \\
\text { population (\%) }\end{array}$ \\
\hline Age & \multicolumn{2}{|c|}{ Mean: 53.9 \pm 13.6 years } \\
\hline Gender & \multicolumn{2}{|c|}{} \\
\hline Male & 191 & 22.5 \\
\hline Female & 657 & 77.5 \\
\hline Type of cancer & & \\
\hline Breast & 425 & 50.1 \\
\hline Cervical & 94 & 11.1 \\
\hline Colorectal & 53 & 6.3 \\
\hline Prostate & 41 & 4.8 \\
\hline Ovarian & 22 & 2.6 \\
\hline Others & 213 & 25.1 \\
\hline Comorbidities & & \\
\hline Present & 228 & 26.9 \\
\hline Absent & 620 & 73.1 \\
\hline
\end{tabular}


Table 1. Continued.

\begin{tabular}{|c|c|c|}
\hline $\begin{array}{l}\text { Treatment } \\
\text { characteristics }\end{array}$ & & \\
\hline Chemotherapy & & \\
\hline Yes & 687 & 81.0 \\
\hline No & 161 & 19.0 \\
\hline Radiotherapy & & \\
\hline Yes & 332 & 39.1 \\
\hline No & 516 & 60.9 \\
\hline Surgery & & \\
\hline Yes & 380 & 44.8 \\
\hline No & 468 & 55.2 \\
\hline
\end{tabular}

Table 2. Distribution of comorbidities based on the age-adjusted hypertension-augmented $\mathrm{CCl}, n=848$.

\begin{tabular}{|l|c|c|}
\hline \multicolumn{1}{|c|}{ Attribute } & Frequency & Percentage \\
\hline Myocardial infarction & 5 & 0.6 \\
\hline Congestive heart failure & 9 & 1.1 \\
\hline Peripheral vascular disease & 2 & 0.2 \\
\hline Cerebrovascular disease & 2 & 0.2 \\
\hline Dementia & 2 & 0.2 \\
\hline Chronic pulmonary disease & 4 & 0.5 \\
\hline Rheumatic disease & 0 & 0.0 \\
\hline Peptic ulcer disease & 18 & 2.1 \\
\hline Mild liver disease & 2 & 0.2 \\
\hline Diabetes mellitus without end-organ damage & 53 & 6.2 \\
\hline Diabetes mellitus with end-organ damage & 4 & 0.5 \\
\hline Hemiplegia & 4 & 0.5 \\
\hline Renal disease & 2 & 0.2 \\
\hline Lymphoma & 7 & 0.8 \\
\hline Leukaemia & 2 & 0.2 \\
\hline Moderate liver disease & 2 & 0.2 \\
\hline Acquired immunodeficiency syndrome & 5 & 0.6 \\
\hline Hypertension & 173 & 20.4 \\
\hline
\end{tabular}

Table 3. Distribution of $\mathrm{CCl}$ scores among cancer patients with their relative risks of death within 1 year (relative risk figures from Charlson et al [30]).

\begin{tabular}{|c|c|c|c|}
\hline $\mathrm{CCl}$ score & $\boldsymbol{n = 8 4 8 ( \% )}$ & $\begin{array}{c}\text { Estimated relative risk of death } \\
\text { within 1 year }\end{array}$ & $\mathbf{9 5 \% \text { confidence interval }}$ \\
\hline $\mathbf{0}$ & $132(15.6)$ & 1.00 & - \\
\hline $\mathbf{1}$ & $183(21.6)$ & 1.45 & $1.25-1.60$ \\
\hline
\end{tabular}


Table 3. Continued.

\begin{tabular}{|c|c|c|c|}
\hline $\mathbf{2}$ & $175(20.6)$ & 2.10 & $1.57-2.81$ \\
\hline $\mathbf{3}$ & $169(19.9)$ & 3.04 & $1.96-4.71$ \\
\hline $\mathbf{4}$ & $114(13.4)$ & 4.40 & $2.45-7.90$ \\
\hline $\mathbf{5}$ & $56(6.6)$ & 6.38 & $3.07-13.2$ \\
\hline $\mathbf{6}$ & $14(1.7)$ & 9.23 & $3.84-22.20$ \\
\hline $\mathbf{7}$ & $3(0.4)$ & 13.37 & $4.81-37.22$ \\
\hline $\mathbf{9}$ & $2(0.2)$ & - & - \\
\hline
\end{tabular}

Table 4. Distribution of cancer types by mean $\mathrm{CCl}$ scores and mean ages.

\begin{tabular}{|l|c|c|}
\hline \multicolumn{1}{|c|}{ Type of cancer } & Mean CCl score & Age \\
\hline Prostate & $3.7 \pm 1.2$ & $66.5 \pm 8.7$ \\
\hline Lung & $3.4 \pm 1.2$ & $66.2 \pm 10.8$ \\
\hline Pancreas & $3.0 \pm 1.2$ & $61.4 \pm 12.0$ \\
\hline Endometrial & $2.7 \pm 1.3$ & $58.5 \pm 9.9$ \\
\hline Cervical & $2.4 \pm 1.4$ & $56.0 \pm 12.6$ \\
\hline Liver & $2.2 \pm 1.7$ & $53.9 \pm 13.8$ \\
\hline Colorectal & $2.2 \pm 1.6$ & $52.8 \pm 13.9$ \\
\hline Breast & $2.0 \pm 1.5$ & $52.4 \pm 12.7$ \\
\hline Nasopharyngeal & $1.8 \pm 1.4$ & $48.7 \pm 14.8$ \\
\hline Ovarian & $1.5 \pm 1.4$ & $51.2 \pm 16.5$ \\
\hline
\end{tabular}

Table 5. Relationships between mean $\mathrm{CCl}$ scores and age or treatment options.

\begin{tabular}{|c|c|c|c|}
\hline Variable & $n$ & Mean $\mathrm{CCl}$ & $p$-value \\
\hline \multicolumn{4}{|l|}{ Age } \\
\hline$\leq 50$ years & 356 & $0.8 \pm 0.9$ & \multirow[t]{2}{*}{$0.00001^{*}$} \\
\hline$\geq 51$ years & 492 & $3.3 \pm 1.2$ & \\
\hline \multicolumn{4}{|l|}{ Chemotherapy } \\
\hline No & 161 & $2.5 \pm 1.9$ & \multirow[t]{2}{*}{$0.05^{*}$} \\
\hline Yes & 687 & $2.2 \pm 1.6$ & \\
\hline \multicolumn{4}{|l|}{ Surgery } \\
\hline No & 468 & $2.4 \pm 1.7$ & \multirow[t]{2}{*}{$0.01^{*}$} \\
\hline Yes & 380 & $2.1 \pm 1.5$ & \\
\hline \multicolumn{4}{|l|}{ Radiotherapy } \\
\hline No & 516 & $2.2 \pm 1.6$ & \multirow[t]{2}{*}{0.52} \\
\hline Yes & 332 & $2.3 \pm 1.6$ & \\
\hline
\end{tabular}

*Significant $p$-values 


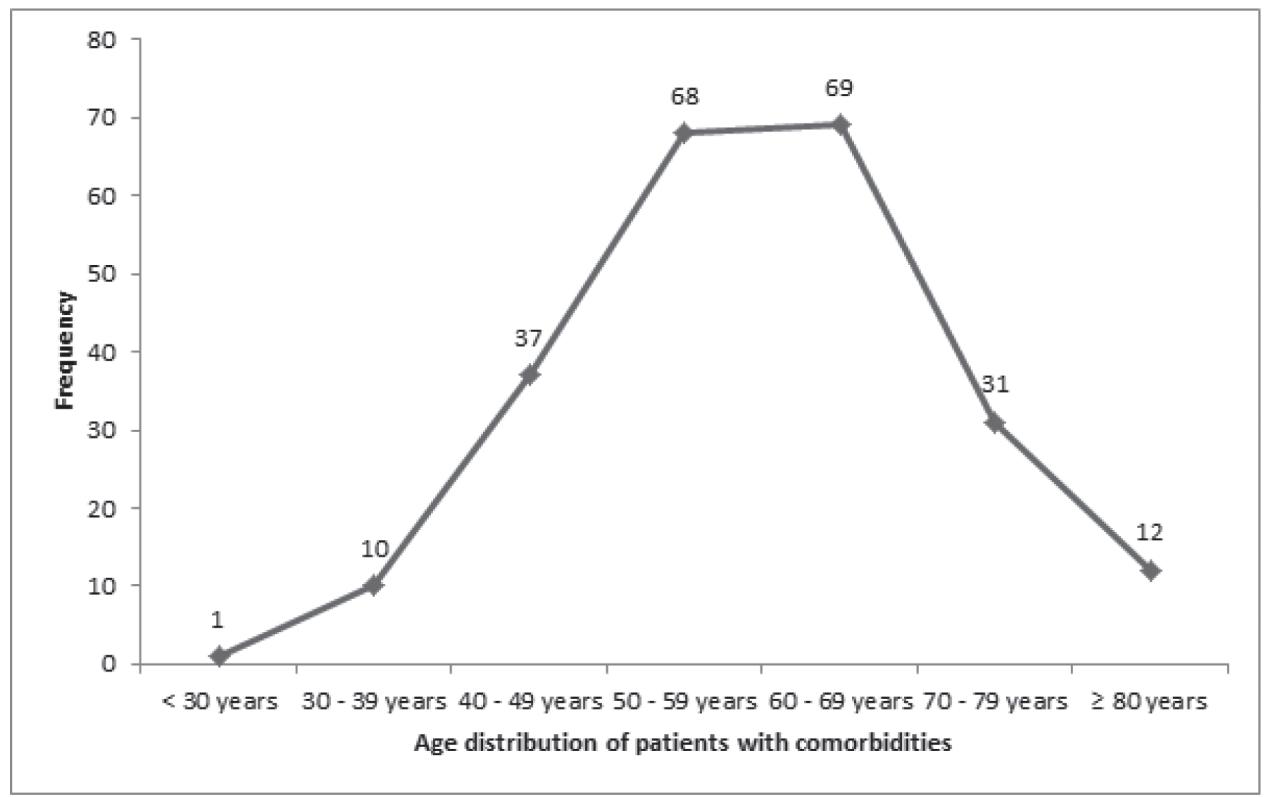

Figure 1. Age distribution of comorbidities in the study population.

\section{Discussion}

The $\mathrm{CCl}$ has been used extensively to assess comorbidity burden across populations [33], assess risk of mortality in groups of patients [10], predict costs of treating chronic illnesses [17, 34], and predict a variety of malignancies and other clinical outcomes. From the results obtained, about a quarter of the patients $(26.9 \%)$ had at least a comorbid illness. Studies have pointed out a wide range of comorbidities in cancer patients, from as low as $0.4 \%$ to as high as $90 \%[35,36]$. This huge variability in the prevalence of comorbidities suggests that the prevalence of comorbidity may be influenced by specific factors such as age, geographical location, race/ethnicity and socioeconomic status.

The influence of age on the prevalence of comorbidity is demonstrated by a Nigerian study conducted on 249 elderly patients in Zaria which showed that $38.2 \%$ of the patients had comorbid conditions [37]. This is much higher than the $26.9 \%$ obtained in this study, and this may be due to the fact that just $58.0 \%$ of the patients in this study were older than 50 years, indicating a significant population of younger patients in this study as compared with those in the Zaria study in which over $90 \%$ were older than 50 years. Studies focused on older patients tend to report a higher level of comorbidity while those based on administrative data or medical notes in which a wider range of ages are found tend to present a lower prevalence of comorbidity [36]. Unsurprisingly, a significant difference in the mean CCI scores between patients $\leq 50$ years and those $>50$ years $(p<0.05)$ was found in this study. This implies that patients who are at least 50 years must be evaluated for the presence of comorbidities at presentation for a malignancy.

In close relation to the effect of age on the prevalence of comorbidity is the distribution of comorbidities as the most common comorbidity experienced by these patients was hypertension (173, 20.4\%). This was followed by diabetes mellitus and peptic ulcer disease in $53(6.2 \%)$ and $18(2.1 \%)$ patients, respectively. In the study by Adewuyi et al [37], hypertension was the most common comorbidity found amongst elderly cancer patients, and followed by diabetes mellitus. This was not surprising as both hypertension and diabetes are chronic conditions that are commonly found among elderly individuals [38]. While both conditions are not usually life threatening in the short term, their co-occurrence with a malignancy alters the prognosis and indicates the need for more specialised care, and especially, a multidisciplinary approach to care $[31,36,37]$. 
Also, the type of cancer has been found to influence both the presence and magnitude of comorbidity. In this study, prostate cancer had the highest mean $\mathrm{CCl}$ with $3.7 \pm 1$.2. Breast cancer, which was the most prevalent type of cancer, occurring in over half of the patients, had a mean $\mathrm{CCl}$ of $2.0 \pm 1.5$. In between were lung (3.4 \pm 1.2$)$, pancreas $(3.0 \pm 1.2)$ and endometrial $(2.7 \pm 1.3)$ cancers. Edwards et al [39] had previously reported that patients with prostate and breast cancer tend to have similar levels of comorbidity while lung cancer patients had a much greater level of comorbidity. Using risk factors, they had concluded that cancers strongly associated with chronic risk factors such as smoking were at one end of the comorbidities spectrum while cancers less (or inversely) associated with risk factors (e.g. prostate and breast cancers) were at the other end of the spectrum. This does not appear to be so from the results of this study, in which prostate and breast cancers were on different ends of the comorbidities spectrum. This is likely due to the influence of age, as the mean age for patients with prostate cancer was $66.5 \pm 8.7$ years as against $52.4 \pm 12.7$ years for those with breast cancer.

In the past, studies have suggested that the presence of comorbidities determine treatment choices. According to Sarfati et al [36], patients who have significant comorbidities are generally less likely to be offered curative treatment for their primary malignant conditions than those without. For instance, it has been shown that the offer and uptake of chemotherapy in patients with colorectal cancer is relatively lower in those who have comorbidities regardless of age [40-42]. This was found to be true in this study as mean CCls of those who did not receive chemotherapy was significantly higher than those who were given chemotherapy. This implies that patients with less number of comorbidities were more likely to be given chemotherapy. The same significant difference was obtained for surgical treatment, although the relationship between comorbidities and surgical treatment is less clear as some studies have reported no association while others suggest an inverse relationship between the presence or level of comorbidity and surgery [36, 43,44]. For radiotherapy, there was no statistically significant difference in the mean $\mathrm{CCl}$ scores of those who received radiotherapy and those who did not.

A number of reasons have been proposed to explain the influence of comorbidity on treatment choices, offering and uptake. It has been shown that the toxicity and side effects of chemotherapy and radiotherapy may be increased with the presence of co-existing illnesses [36]. Other clinicians have suggested that the life expectancy of cancer patients worsened by comorbidities is not sufficient to justify the use of curative but potentially toxic treatment options [40, 45-47]. Even though there have been clear associations between the presence of comorbidity and the choice of chemotherapeutic/surgical treatments in this study, this is not as clear cut in oncology clinics as significant inconsistencies in the determination of treatment options for cancer patients might have contributed to the differences rather than a simple consideration of the extent or presence of a comorbidity. Nonetheless, not all patients with significant comorbidities or advanced age should be excluded from more aggressive cancer treatment options they desperately need.

Many studies have related $\mathrm{CCl}$ scores with the risk of mortality in cancer patients. Comorbidities worsen the quality of life of patients with cancer, and also increase their chances of dying earlier [48-50]. The $\mathrm{CCl}$ has been shown to be a very strong and accurate predictor of mortality within 1, 5 and 10 years. On the basis of this, it is clear that the majority of these patients have a significant relative risk of death, ranging from 1.45 to 13.37. Since the bulk of the patients have $\mathrm{CCl}$ scores between 1 and 3 , their 10-year survival rates would range from as low as $45 \%$ to as high as $73 \%$. Also, the association between CCl scores and mortality has been linked to associations with quality of life and performance status (PS) [48-52]. Mayr et al [52] found that the CCl and Eastern Cooperative Oncology Group (ECOG) were strong predictors for postoperative mortality in bladder cancer. In future studies, it will be interesting to see a direct correlation between the $\mathrm{CCl}$ and PS indices such as the ECOG or the Karnofsky scale considering that they are standard indices in clinical practice and research for quantifying the aggregate impact of comorbidities on the quality of life of cancer patients.

While considering the significant frequency of comorbidities noted in the population studied, and the strength of association between comorbidities and treatment options, it is important to note some of the limitations of this study. This study utilised a retrospective design which makes it difficult to estimate treatment outcomes and overall survival like it has been done in some other studies. This also made it difficult to evaluate the relationships between common comorbidities such as hypertension or diabetes and survival. It is also understood that the severity of each comorbid condition determines how it affects the cancer patient, more so, that the effect of a comorbid condition varies across cancer types and treatments.

\section{Conclusion}

A significant proportion of cancer patients in Lagos suffer from one or more comorbidities which influences their treatment and overall clinical outcomes. Hence, there is a need to evaluate cancer patients for comorbidities with the aim of instituting appropriate multidisciplinary management measures where necessary. 
ecancer 2018, 12:843

\section{Funding acknowledgment}

None.

\section{Disclaimer}

The views expressed in the submitted article are solely our own and not an official position of any institution or funder.

\section{References}

1. Ferlay J, Soerjomataram I, and Ervik M, et al (2013) GLOBOCAN 2012 v1.0, Cancer Incidence and Mortality Worldwide: IARC CancerBase No. 11 [Internet] Lyon, France: International Agency for Research on Cancer [http://globocan.iarc.fr] Date accessed: $21 / 02 / 17$

2. World Health Organization (2017) Cancer fact sheet World Health Organization [http://www.who.int/mediacentre/factsheets/fs297/en/] Date accessed: 27/02/17

3. Bellizzi KM and Rowland $\mathrm{JH}$ (2007) The role of comorbidity, symptoms and age in the health of older survivors following treatment for cancer Aging Health 3(5) 625-635 https://doi.org/10.2217/1745509X.3.5.625

4. Bjorgul K, Novicoff WM, and Saleh KJ (2010) Evaluating comorbidities in total hip and knee arthroplasty: available instruments J Orthop Traumatol 11(4) 203-209. https://doi.org/10.1007/s10195-010-0115-x PMID: 21076850 PMCID: 3014469

5. Piccirillo JF and Feinstein AR (1996) Clinical symptoms and comorbidity: significance for the prognostic classification of cancer Cancer 77 834-842 PMID: $\underline{8608472}$

6. Feinstein AR (1970) The pre-therapeutic classification of co-morbidity in chronic disease J Chronic Dis 23 455-469 https://doi. org/10.1016/0021-9681(70)90054-8 PMID: 26309916

7. Lund L, Borre M, and Jacobsen J, et al (2008) Impact of comorbidity on survival of danish prostate cancer patients, 1995-2006: a population-based cohort study Urology 72 1258-1262 https://doi.org/10.1016/j.urology.2007.12.018 PMID: 18342917

8. Patniak JL, Byers T, and DiGuiseppi C, et al (2011) The influence of comorbidities on overall survival among older women diagnosed with breast cancer J Natl Cancer Inst 103 1101-1111 https://doi.org/10.1093/inci/djr188

9. Hurria A, Leung D, and Trainor K, et al (2003) Factors influencing treatment patterns of breast cancer patients age 75 and older Crit Rev Oncol Hematol 46 121-126 https://doi.org/10.1016/S1040-8428(02)00133-6 PMID: 12711357

10. Koppie TM, Serio AM, and Vickers AJ, et al (2008) Age-adjusted Charlson comorbidity score is associated with treatment decisions and clinical outcomes for patients undergoing radical cystectomy for bladder cancer Cancer 112 2384-2392 https://doi.org/10.1002/cncr.23462 PMID: 18404699

11. Jørgensen TL, Hallas J, and Friis S, et al (2012) Comorbidity in elderly cancer patients in relation to overall and cancer-specific mortality Br J Cancer 106 1353-1360 https://doi.org/10.1038/bjc.2012.46 PMID: 22353805 PMCID: 3314782

12. Bjerager M, Palshof $\mathrm{T}$, and Dahl R, et al (2006) Delay in diagnosis of lung cancer in general practice Br J Gen Pract 56 $863-868$ PMID: 17132354 PMCID: 1927095

13. Fleming ST, Pursley HG, and Newman B, et al (2005) Comorbidity as a predictor of stage of illness for patients with breast cancer Med Care 43 132-140 https://doi.org/10.1097/00005650-200502000-00006 PMID: 15655426 
14. Kim J, Kim S, and Albergotti WG, et al (2015) Selection of ideal candidates for surgical salvage of head and neck squamous cell carcinoma: effect of the Charlson-age comorbidity index and oncologic characteristics on 1-year survival and hospital course JAMA Otolaryngol Head Neck Surg 141(12) 1059-1065 https://doi.org/10.1001/jamaoto.2015.2158 PMID: 26447790 PMCID: $\underline{4884653}$

15. Melvan JN, Sancheti MS, and Gillespie T, et al (2015) Nonclinical factors associated with 30-day mortality after lung cancer resection: an analysis of $\mathbf{2 1 5 , 0 0 0}$ patients using the national cancer data base $J$ Am Coll Surg 221 550-563 https://doi. org/10.1016/j.jamcollsurg.2015.03.056 PMID: 26206651 PMCID: $\underline{4514912}$

16. Datema FR, Ferrier MB, and van der Schroeff MP, et al (2010) Impact of comorbidity on short-term mortality and overall survival of head and neck cancer patients Head Neck 32 728-736

17. Yoon SJ, Kim EJ, and Seo HJ, et al (2015) The association between Charlson comorbidity index and the medical care cost of cancer: a retrospective study Biomed Res Int 2015259341 https://doi.org/10.1155/2015/259341 PMID: 26347086 PMCID: 4539424

18. Piccirillo JF, Tierney RM, and Costas I, et al (2004) Prognostic importance of comorbidity in a hospital-based cancer registry JAMA 291(20) 2441-2447 https://doi.org/10.1001/jama.291.20.2441 PMID: 15161894

19. Chou WC, Chang PH, and $\mathrm{Lu} \mathrm{CH}$, et al (2016) Effect of comorbidity on postoperative survival outcomes in patients with solid cancers: a 6-year multicenter study in Taiwan J Cancer 7(7) 854-861 https://doi.org/10.7150/jca.14777 PMID: 27162545 PMCID: $\underline{4860803}$

20. Uijen AA and van de Lisdonk EH (2008) Multimorbidity in primary care: prevalence and trend over the last 20 years Eur J Gen Pract 14 28-32 https://doi.org/10.1080/13814780802436093 PMID: 18949641

21. Barnett K, Mercer SW, and Norbury M, et al (2012) Epidemiology of multimorbidity and implications for health care, research, and medical education: a cross-sectional study Lancet 380 37-43 https://doi.org/10.1016/S0140-6736(12)60240-2 PMID: 22579043

22. Adenipekun A, Elumelu-Kupoluyi T, and Omoyeni N, et al (2012) Knowledge and experience of cancer patients receiving chemotherapy in a teaching hospital in Nigeria Internet J Pain Symp Control Palliat Care 9(1) 1

23. Bray F, Ren JS, and Masuyer E, et al (2013) Estimates of global cancer prevalence for $\mathbf{2 7}$ sites in the adult population in 2008 Int J Cancer 132(5) 1133-1145 https://doi.org/10.1002/ijc.27711

24. Maiyaki MB and Garbati MA (2014) The burden of non-communicable diseases in Nigeria; in the context of globalization Ann Afr Med 13(1) 1-10 https://doi.org/10.4103/1596-3519.126933 PMID: 24521570

25. World Health Organization (2010) Non-communicable Diseases (NCD) Country Profile - Nigeria [http://www.who.int/nmh/countries/nga en.pdf?ua=1] Date accessed: 02/06/17

26. WoolcockAJ (1989) Epidemiology of chronic airways disease Chest96302S-306S https://doi.org/10.1378/chest.96.3 Supplement.302S PMID: 2766849

27. Desalu OO, Oluboyo PO, and Salami AK (2009) The prevalence of bronchial asthma among adults in llorin, Nigeria Afr J Med Med Sci 38 149-154

28. Erhabor GE, Agbroko SO, and Bamigboye $P$, et al (2006) Prevalence of asthma symptoms among university students 15 to 35 years of age in Obafemi Awolowo University, Ile-Ife, Osun State J Asthma 43 161-164 https://doi.org/10.1080/02770900500499046 PMID: $\underline{16517434}$

29. World Health Organization (2013) WHO Statistical Information System, 2012 World Health Organization [http://nigeria.opendataforafrica.org/yltgnw/nigeria-chronic-diseases] Date accessed: 27/09/17

30. Charlson ME, Szatrowski TP, and Peterson J, et al (1994) Validation of a combined comorbidity index J Clin Epidemiol 47(11) 1245-1251 https://doi.org/10.1016/0895-4356(94)90129-5 PMID: 7722560 
31. Hall WH, Ramachandran R, and Narayan S, et al (2004) An electronic application for rapidly calculating Charlson comorbidity score BMC Cancer 494 https://doi.org/10.1186/1471-2407-4-94 PMID: 15610554 PMCID: 545968

32. Jung SY, Rosenzweig M, and Linkov F, et al (2012) Comorbidity as a mediator of survival disparity between younger and older women diagnosed with metastatic breast cancer Hypertension 59(2) 205-211 https://doi.org/10.1161/HYPERTENSIONAHA.111.171736

33. D'Hoore W, Bouckaert A, and Tilquin C (1996) Practical considerations on the use of the charlson comorbidity index with administrative data bases J Clin Epidemiol 49(12) 1429-1433 https://doi.org/10.1016/S0895-4356(96)00271-5

34. Charlson ME, Charlson RE, and Peterson JC, et al (2008) The Charlson comorbidity index is adapted to predict costs of chronic disease in primary care patients J Clin Epidemio/ 61(12) 1234-1240 https://doi.org/10.1016/j.jclinepi.2008.01.006 PMID: 18619805

35. Lee L, Cheung WY, and Atkinson E, et al (2011) Impact of comorbidity on chemotherapy use and outcomes in solid tumors: a systematic review J Clin Oncol 29 106-117 https://doi.org/10.1200/JCO.2010.31.3049

36. Sarfati D, Koczwara B, and Jackson C (2016) The impact of comorbidity on cancer and its treatment Cancer J Clin 66 337-350 https://doi.org/10.3322/caac.21342

37. Adewuyi SA, Oguntayo AO, and Samaila MO, et al (2016) Sociodemographic and clinicopathologic characteristics of 249 elderly cancer patients seen at the Radiotherapy and Oncology Department, Ahmadu Bello University Teaching Hospital, Zaria, Nigeria Arch Int Surg 6 22-27 https://doi.org/10.4103/2278-9596.187194

38. Balogun WO and Salako BL (2011) Co-occurrence of diabetes and hypertension: pattern and factors associated with order of diagnosis among Nigerians Ann Ib Postgrad Med 9(2) 89-93 PMID: 25161490 PMCID: 4111031

39. Edwards BK, Noone AM, and Mariotto AB, et al (2014) Annual Report to the Nation on the status of cancer, 1975-2010, featuring prevalence of comorbidity and impact on survival among persons with lung, colorectal, breast, or prostate cancer Cancer 120 1290-1314 https://doi.org/10.1002/cncr.28509

40. Gross CP, McAvay GJ, and Guo Z, et al (2007) The impact of chronic illnesses on the use and effectiveness of adjuvant chemotherapy for colon cancer Cancer 109 2410-2419 https://doi.org/10.1002/cncr.22726 PMID: 17510973

41. Sarfati D, Hill S, and Blakely T, et al (2009) The effect of comorbidity on the use of adjuvant chemotherapy and survival from colon cancer: a retrospective cohort study BMC Cancer 9116 https://doi.org/10.1186/1471-2407-9-116 PMID: 19379520 PMCID: 2678274

42. Khrizman P, Niland JC, and ter Veer A, et al (2013) Postoperative adjuvant chemotherapy use in patients with stage II/III rectal cancer treated with neoadjuvant therapy: a National Comprehensive Cancer Network analysis J Clin Oncol 31 30-38 https://doi.org/10.1200/JCO.2011.40.3188

43. Iversen LH, Norgaard M, and Jacobsen J, et al (2009) The impact of comorbidity on survival of Danish colorectal cancer patients from 1995 to 2006-a population-based cohort study Dis Colon Rectum 52 71-78 https://doi.org/10.1007/DCR.0b013e3181974384 PMID: 19273959

44. Zhang W, Ayanian JZ, and Zaslavsky AM (2007) Patient characteristics and hospital quality for colorectal cancer surgery Int $J$ Qual Health Care 19 11-20 https://doi.org/10.1093/intqhc/mzl047

45. Lemmens VE, Janssen-Heijnen ML, and Verheij CD, et al (2005) Co-morbidity leads to altered treatment and worse survival of elderly patients with colorectal cancer Br J Surg 92 615-623 https://doi.org/10.1002/bjs.4913 PMID: 15779071

46. Schrag D, Cramer LD, and Bach PB, et al (2001) Age and adjuvant chemotherapy use after surgery for stage III colon cancer J Natl Cancer Inst 93 850-857 https://doi.org/10.1093/jnci/93.11.850 PMID: 11390534

47. Kutner JS, Vu KO, and Prindiville SA, et al (2000) Patient age and cancer treatment decisions. Patient and physician views Cancer Pract 8 114-119 https://doi.org/10.1046/j.1523-5394.2000.83004.x 
48. Fortin M, Bravo G, and Hudon C, et al (2006) Relationship between multimorbidity and health-related quality of life of patients in primary care Qual Life Res 15 83-91 https://doi.org/10.1007/s11136-005-8661-z PMID: 16411033

49. Fortin M, Lapointe L, and Hudon C, et al (2004) Multimorbidity and quality of life in primary care: a systematic review Health Qual Life Outcomes 251 https://doi.org/10.1186/1477-7525-2-51 PMID: 15380021 PMCID: $\underline{526383}$

50. Mukherjee $\mathrm{B}, \mathrm{Ou} \mathrm{H}$, and Wang $\mathrm{F}$, et al (2011) A new comorbidity index: the health-related quality of life comorbidity index $J$ Clin Epidemiol 64 309-319 https://doi.org/10.1016/j.jclinepi.2010.01.025

51. Chou WC, Liu KH, and Lu CH, et al (2016) To operate or not: prediction of 3-month postoperative mortality in geriatric cancer patients J Cancer 7(1) 14-21 https://doi.org/10.7150/jca.13126 PMID: 26722355 PMCID: 4679376

52. Mayr R, May M, and Martini T, et al (2012) Predictive capacity of four comorbidity indices estimating perioperative mortality after radical cystectomy for urothelial carcinoma of the bladder BJU Int 110(6 Pt B) E222-E227 https://doi.org/10.1111/j. 1464410X.2012.10938.x PMID: 22314129 